\title{
Collaboration and Interoperability Support for Agile Enterprises in a Networked World: Emerging Scenarios, Research Challenges, Enabling Technologies
}

\author{
Manfred Reichert \\ University of Ulm, 89069 Ulm, Germany \\ manfred.reichert@uni-ulm.de
}

\begin{abstract}
The economic success of enterprises increasingly depends on their ability to react to changes in their environment in a quick and flexible way. Examples of such environmental changes include regulatory adaptations (e.g. introduction of Sarbanes-Oxley or Basel II), market evolution, altered customer behavior, process improvement, and strategy shifts. Companies have therefore identified business agility as a competitive advantage required for coping with business trends like increasing product and service variability, faster time-tomarket, and increasing division of labor along the supply chain. In particular, the agile enterprise should be able to quickly set up new business processes as well as to adapt existing ones. However, networked enterprises must not accomplish such business process changes independent from the interactions they have with their partners and customers; e.g., business contracts and business compliance rules must be ensured after business process changes as well. This keynote will discuss major research challenges to be tackled in this context. Further, it will present advanced methods, concepts and technologies enabling collaboration and interoperability support for the agile enterprise in a networked world.
\end{abstract}

Keywords: networked enterprises, collaboration, interoperability, agility, business process change, business process compliance.

\section{Brief Biography}

Manfred Reichert is professor at the University of Ulm, Germany and co-director of the Institute of Databases and Information Systems.

His major research interests are next generation process management technology (e.g., adaptive processes, process variability, data-driven and object-centric processes, mobile processes), service-oriented computing (e.g., service interoperability, service evolution), and advanced applications for flexible information systems (e.g., e-health and automotive engineering).

Together with Peter Dadam he pioneered the work on the ADEPT process management technology and he is co-founder of the AristaFlow GmbH. Manfred has been participating in numerous research projects in the BPM area and contributed more than 200 scientific papers on BPM-related topics. His book entitled "Enabling 
Flexibility in Process-Aware Information Systems" was published by Springer in September 2012. Manfred has been PC Co-Chair of the BPM'08, CoopIS'11, and EDOC'13 conferences and General Chair of the BPM'09 conference.

\section{References}

1. Reichert, M., Weber, B.: Enabling Flexibility in Process-Aware Information Systems: Challenges, Methods, Technologies. Springer (2012)

2. Reichert, M., Rinderle-Ma, S., Dadam, P.: Flexibility in Process-Aware Information Systems. In: Jensen, K., van der Aalst, W.M.P. (eds.) ToPNoC II. LNCS, vol. 5460, pp. 115-135. Springer, Heidelberg (2009)

3. Dadam, P., Reichert, M.: The ADEPT Project: A Decade of Research and Development for Robust and Flexible Process Support - Challenges and Achievements. Computer Science - R \& D 23(2), 81-97

4. Knuplesch, D., Reichert, M., Mangler, J., Rinderle-Ma, S., Fdhila, W.: Towards Compliance of Cross-Organizational Processes and Their Changes. In: La Rosa, M., Soffer, P. (eds.) BPM Workshops 2012. LNBIP, vol. 132, pp. 649-661. Springer, Heidelberg (2013)

5. Fdhila, W., Rinderle-Ma, S., Reichert, M.: Change Propagation in Collaborative Processes Scenarios. In: Proc. 8th IEEE Int'l Conf. on Collaborative Computing (CollaborateCom 2012), Pittsburgh, USA (2012)

6. Knuplesch, D., Pryss, R., Reichert, M.: Data-Aware Interaction in Distributed and Collaborative Workflows: Modeling, Semantics, Correctness. In: Proc. 8th IEEE Int'l Conf. on Collaborative Comp (CollaborateCom 2012), Pittsburgh, USA (2012)

7. Rinderle, S., Wombacher, A., Reichert, M.: Evolution of Process Choreographies in DYCHOR. In: Meersman, R., Tari, Z. (eds.) OTM 2006. LNCS, vol. 4275, pp. 273-290. Springer, Heidelberg (2006)

8. Rinderle, S., Wombacher, A., Reichert, M.: On the Controlled Evolution of Process Choreographies. In: Proc. 22nd Int'l Conf. on Data Engineering (ICDE 2006), Atlanta, USA, p. 124. IEEE Comp Society Press (2006)

9. Ly, L.T., Knuplesch, D., Rinderle-Ma, S., Göser, K., Pfeifer, H., Reichert, M., Dadam, P.: SeaFlows Toolset - Compliance Verification Made Easy for Process-Aware Information Systems. In: Soffer, P., Proper, E. (eds.) CAiSE Forum 2010. LNBIP, vol. 72, pp. 76-91. Springer, Heidelberg (2011)

10. Mutschler, B., Reichert, M., Bumiller, J.: Unleashing the Effectiveness of Process-oriented Information Systems: Problem Analysis, Critical Success Factors and Implications. IEEE Trans. on Systems, Man, and Cybernetics (Part C) 38(3), 280-291 (2008) 